\title{
Model Development in Assessing the Career Path of Senior High School Students in Philippine Setting
}

\author{
Jheanel E. Estrada, Glenwin G. Bernabe, Jason S. Lopez, and Joyce Anne S. Potestades
}

\begin{abstract}
Choosing the right career is significant in the life of every person and especially before entering college. Many students have chosen their career path without a proper prior advice from a guidance counselor. They're overlooking the NCAE, surveys, and different exams in helping them find their right career. It may potentially cause some lapses in their academic performance, mismatch with their personality, interest, and abilities. To give the students some guidance, it is important to create a system that provides direction in choosing a career path. The use of an image type questionnaire will significantly boost the interaction between the students and make them more attentive in answering the questions. The different factors and attributes will give some weight in assessing the career path of the student. Hence, not only their skills, and attitude will affect the outcome of the career. By implementing this system, it will involve the student much more, and for that matter, a much better result will be produced.
\end{abstract}

Index Terms-Data mining, pattern recognition, SHS, visualization,

\section{INTRODUCTION}

Ref. [1] in the the year 2016, according to the Department of Labor and Employment (DOLE) showed that out of the $4,239,392$ domestic and international job vacancies offered in thousands of job fairs nationwide in the past two years, only 391,088 among 1,286,073 applicants were hired on the spot. Also, [2] DOLE records in 2015, which showed that roughly 135,590 were hired out of the 487,640 applicants in the 1,661 job fairs held nationwide. In 2014, a total of 255,498 people were hired out of the more than 798,000 applicants in the 2,025 job fairs conducted throughout the country. [3] In the past two decades, they found out that the country's unemployment rate has fluctuated between seven to 14 percent. The heightened competition in the market and the lack of adjustments of college and universities trigger the jobs-skills mismatch. Students usually choose their career path based on what their parents want and what they think they want. Most of them are not thinking about the result of their NCAE (National Career Assessment Examination) that determines the career they need to pursue. Skills and attitudes are necessary for establishing your career. That is what they tell us, but there is another aspect that significantly affects in knowing your job. It's analyzing the different patterns, angles, categories, and various fields to correlate it and find out what is the right course for you. The attributes in

Manuscript received April 7, 2017; revised November 25, 2017.

The authors are with the Technological Institute of the Philippines, College of Information Technology Education, Manila, Philippines (e-mail: jheanelestrada29@gmail.com, glenwinbernabe@gmail.com, joycenpotestades@gmail.com). determining the right course will vary. An enormous amount of unemployment and job mismatch happens because people are choosing a career that is not exactly the path which they need to pursue. They need to be serious about it. This kind of problem motivates us to develop an application which sole purpose is to guide students in choosing their career path. Reduce the unemployment rate and job-skill mismatch here in the Philippines because everyone's future will depend on it. Introducing, TrabaWHO: An application that will help the user to determine the best career that will fit their skills, knowledge, and personality.

We all know that there are a lot of factors and attributes can help in determining the career path. This includes skills, attitude, decision- making, home address, educational background, work of their parents, etc. The researchers are trying to use all of the possible attributes that will affect the outcome of the report.

The result of this study will significantly give an idea to a student in choosing the right career path. As job mismatch, social difficulties, dropping out of school or even unemployment can be limited with the proper guidance and attribution to a teenager.

\section{REVIEW OF RELATED LITERATURES AND STUDIES}

According to Kostek [4], assessing yourself as well as your career improves the quality of life. We can also use this information about ourselves to dearly state who we are and what we can do when pursuing career opportunities. In today's buyers job market an engineer must be able to provide an employer with reasons to hire you and not someone else. Career assessment can lead to a better understanding of yourself and your goals. This can become a key element in selling yourself. It can also help you in accepting yourself as you are and not based on the position you hold today or in the future.

There are a lot of ways assessing your characteristics and behaviors to identify the career path that suited you. Due to the advancement of technology, brain-computer interface was used for personal career planner developed by Tan and Chin [5].

The assessment is designed based on Holland code theory to retain the reliability of the career planner. While the assessment taker is answering the questionnaire, the EEG signal from the scalp is recorded by the Emotiv neuroheadger to identify the excitement level. Based on that, the system will then generate the recommended guidance.

As part of the experiment, 20 subjects who are composed of 20 males and 10 females ages 15-30 years old were gathered. 
The EEG signal of the subject is acquired via the 14 electrode from Emotiv neuroheadgear with sampling frequency of $128 \mathrm{~Hz}$.

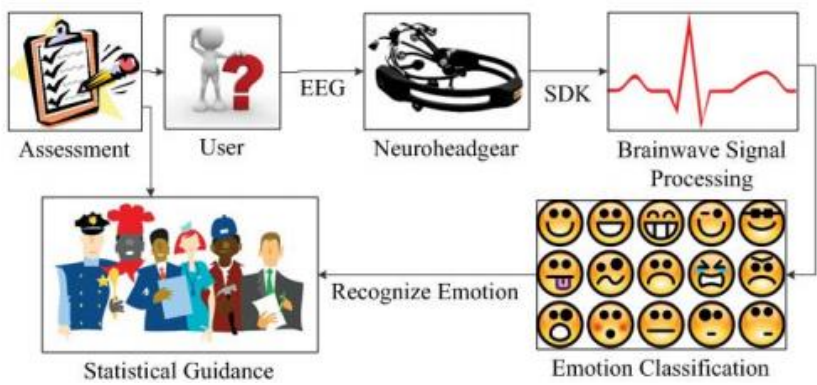

Fig. 1. Overview of the system.

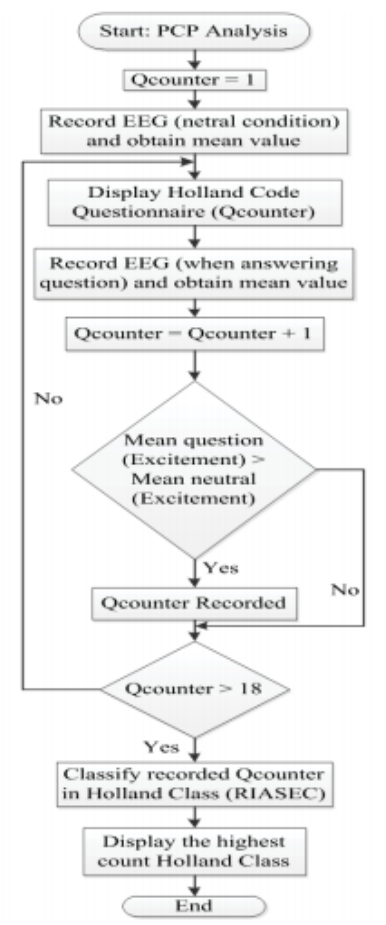

Fig. 2. Flowchart of the system.

According to the flowchart in Fig. 2, the neutral state is recorded prior to any test is given. Subsequently, personality questions are popped up and each excitement state is recorded. Question will hold for 10 seconds and repeated for 18 questions. The question number is recorded if current excitement state is higher than neutral state and discarded when false. The system will then acknowledge the test subject with their personality. 20 test subjects are tested and results are compared with written assessment. The true response indicate that both $\mathrm{BCI}$ and written assessment yield the same results whereas false response indicates that a wrong responses.

This method requires great computational complexity and cost. Therefore, the proponents of this study tries to utilize data mining techniques applicable to the data that were gathered to determine and suggest possible career path of the students in the Philippines.

\section{Methodology}

\section{A. Participants}

Thirty-nine (39) respondents who are currently in senior high school in Technological Institute of the Philippines Manila participated in our study. The participants are composed of thirteen (13) STEM, thirteen (13) HUMSS, and thirteen (13) ABM students. They were all assessed and supervise by the Guidance counselor.

\section{B. Data Gathering Tools}

Prior to data gathering, we developed a mobile application for Android Smartphone (Fig. 3). Developed using Android Studio 2.2 and was designed specifically to get the primary details of the user, give them a survey, and have a result in an instant. Developed and patterned with the RIASEC test.

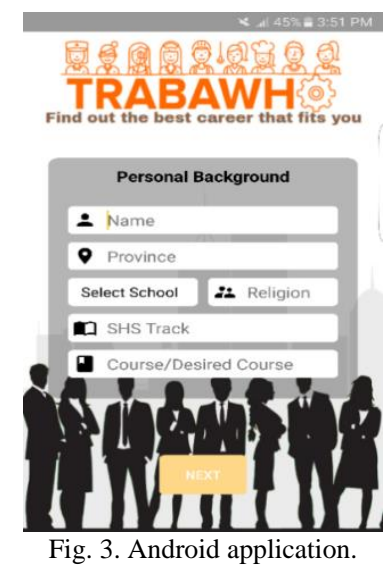

We also developed a web-based application (Fig. 2) on the server side (our laptop) which was used to store data gathered from the smartphones and produce analytics presented in a table and different graphs.

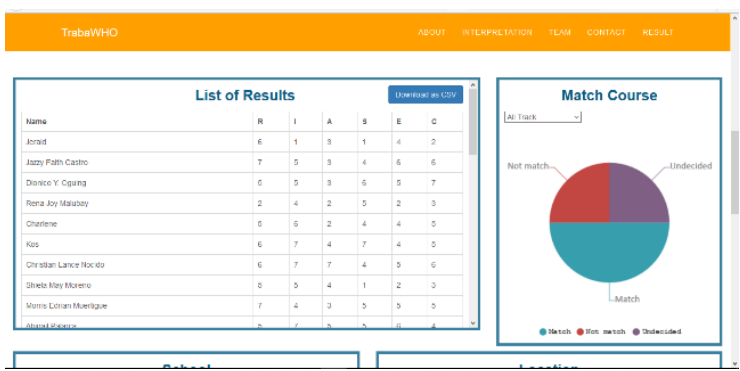

Fig. 4. Web application.

\section{Data Processing}

Out of 39 participants, we divided the datasets into two parts. One is the $80 \%$ of participants which are 30 , and the remaining part is the $20 \%$.

The first group is identified as the training set while the other one is the test set. To make the participants equally distributed between the training set and the test set, the proponents chose the participants of the training set by taking 10 for each senior high school track. Meanwhile, for the test set, the proponents chose 3 senior high school students from each track. The proponents sorted the data according to their track, and they took the first 10 of each track to be included in the training set, and the remaining 3 of each track will be used for the test set.

\section{Model Development and Analytics}

Using RapidMiner tool, model development was conducted using the gathered data from surveys to predict the appropriate course for a certain individual which in this case 
are Senior Highs. The proponents tried different model in training the data. They've used decision tree, default, model, naïve bayes, and generalized linear model. The proponents ended up using a polynomial class of Generalized Linear Model which is the most commonly used in social research.The proponents set the classifier as Split Validation with the use of shuffled sampling as the sampling type to validate the models because it gives the highest accuracy and kappa for the data set.

The overall performance of the models regarding accuracy rate and kappa statistic was presented in Figure 3 and Figure 4 , respectively.

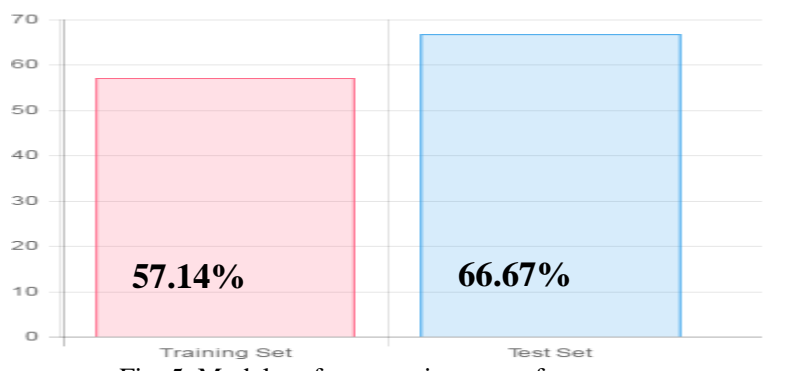

Fig. 5. Model performance in terms of accuracy.

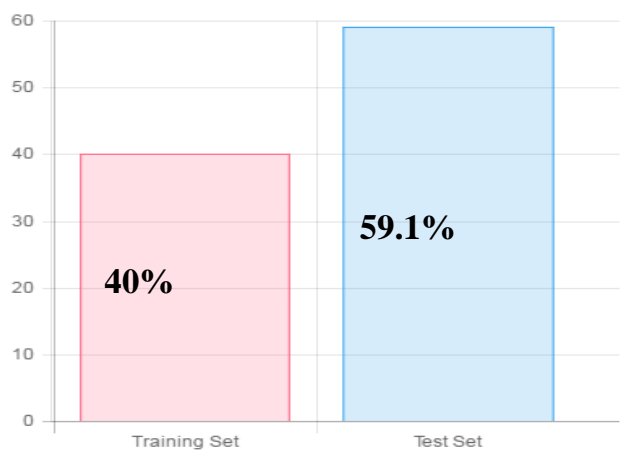

Fig. 6. Model performance in terms of Kappa.

Fig. 5 and 6 shows that Generalized Linear Model shows the highest Accuracy for both training set. Which have an accuracy of $57.14 \%$ for the training set and $66.67 \%$ in the test set.

On the other hand, the kappa is classified as moderately accepted which has $40 \%$ in the training set and $59.1 \%$ in the test set.

\section{CONCLUSION}

The primary objective of this study is to determine the right career of a senior high school student through analyzing the different set of attributes that will affect the overall result. It helped us to determine if the educational attainment of their parents, courses that have enrolled, school where they came from, SHS track, desired program, province, religion, etc will affect the career path of the student.

As shown in Fig. 1 and 2, by using RapidMiner Studio, the proponents are able to detect the attributes that will affect the career path of the student. The best and most acceptable model performance regarding accuracy and kappa was the Generalized Linear Model, classifier of Split Validation, and the use of Split Validation. The model performs an accuracy of $57.14 \%$ and a Kappa of $40 \%$ in training. We're able to garner a $66.67 \%$ on accuracy and $59.1 \%$ on Kappa in the test set. Most of the students have more than one result.

\section{ACKNOWLEDGMENT}

The proponents would like to thank all the persons who assisted in the conduct of this study especially to: - Maria Eloisa Monique Perez, Guidance Counselor, Technological Institute of the Philippines - Manila

\section{REFERENCES}

[1] P. J. Kostek, "Career and life assessment".

[2] T. R. Razak et al., "Career path recommendation system for UiTM perlis students using fuzzy logic," 2011.

[3] C. M. Chang, "Choosing career paths: The outputs of VTASI teams," 2012.

[4] P. J. Kostek, "Career and life assessment," in Proc. the IEEE 1993 National Aerospace and Electronics Conference-NAECON 1993. Dayton, OH, 1993, p. 1037, vol. 2.

[5] H. H. Tan and S. W. Chin, "Personal career planner via brain-computer interface," in Proc. International Conference on Software Intelligence Technologies and Applications \& International Conference on Frontiers of Internet of Things 2014, Hsinchu, 2014, pp. 47-51.

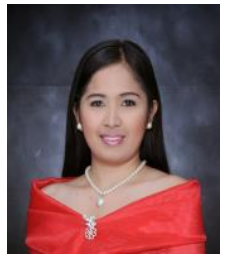

Jheanel E. Estrada was born in June 29, 1992 in Valenzuela city. She earned her bachelor of science in computer science in Technological Institute of the Philippines, Manila and continued her master of science in computer science in Mapua University.

She is a full-time faculty member of the University where she graduated her bachelor's degree. She started working as an instructor and does job as $\mathrm{C}$ language trainer in a private company. She has different papers published in different conferences such as IEEE and ACM.

Ms. Estrada is a member of the Philippines Society of Information Technology Educators since 2012 until the present time.

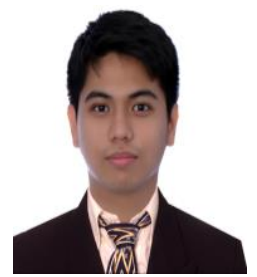

Jason Patrick S. Lopez was born in Sta. Cruz, Laguna on February 23, 1997. He graduated with distinction in Technological Institute of the Philippines, Manila on April 10, 2017, with a degree of bachelor of science in information technology. He joined Eureka!thon Y! which is the corporate incubation program of the PJ Lhuillier Group of Companies as spearheaded by its ICT Arm, Networld Capital Ventures, Inc in Jupiter St, Makati as his internship. They won the competition and are currently working in their startup business which is being funded, mentored, and incubated by PJ Lhuillier Group of Companies.

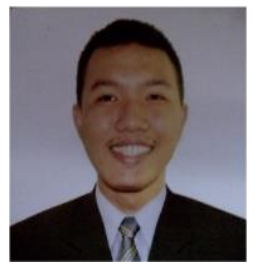

Glenwin G. Bernabe was born at San Fabian, Pangasinan on September 18, 1996. He obtained his bachelor's degree in information technology as cumlaude at Technological Institute of the Philippines in Manila, Philippines this April of 2017.

$\mathrm{He}$ is currently working at Networld Capital Ventures Inc. as a project employee. He and his teammates joined Eureka!thon $\mathrm{Y}$ ! the corporate incubation program of the $\mathrm{PJ}$ Lhuillier Group of Companies as spearheaded by its ICT Arm and the aforementioned in Jupiter St, Makati as his internship. They won the competition and currently his team is currently working on their idea for start-up which is funded by PJLI.

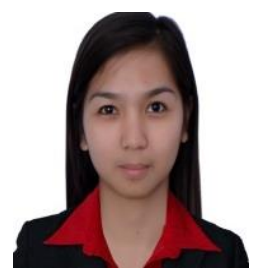

Joyce Ann S. Potestades was born in Infanta, Quezon on 22 October 1997. She graduated from Ungos National High School in Real, Quezon in March 2013, and from Technological Institute of the Philippines at Quiapo Manila with a bachelor of science in information technology in April 2017.

At the last semester of college, she joined Eureka!thon Y!, an incubation program of Networld Capital Ventures Incorporated (NCVI) which is the ICT Arm of PJ Lhuillier Group of Companies and work their as an intern. The aforementioned company funded their project and they are now currently working in their startup business in Makati City, Philippines. 